\title{
Plastic Bottles Waste Utilization as Modifier for Asphalt Mixture Production
}

\author{
Hakeem Jan ${ }^{1, *}$, Mohamad Yusri Aman ${ }^{1}$, and Fazal Karim ${ }^{2}$ \\ ${ }^{1}$ Faculty of Civil and Environmental Engineering, Universiti Tun Hussein Onn Malaysia, 86400 Parit \\ Raja, Johor, Malaysia \\ ${ }^{2}$ Faculty of Civil Engineering, SUIT, 25000 Peshawar, Pakistan
}

\begin{abstract}
Plastic Bottles was used as the polymeric waste to investigate performance of asphalt mixture Aggregates obtained from Margalla, Burhan and Karak quarries. 12 samples were prepared for conventional asphalt mixtures and 48 samples were prepared for PB modified asphalt mixture of each quarries at various proportions of $\mathrm{PB}$ waste. The PB used for modification according to wet process are $15 \%, 20 \%, 25 \%$ and $30 \%$ by weight of Optimum Bitumen Content (OBC). OBC of $4.2 \%$ was concluded for conventional asphalt mixtures. The stability and flow values of the conventional and modified Asphalt Mixture were compared. The average Stability of the modified Margalla asphalt mixtures when $15 \%$ PB was used was much higher as compared to conventional asphalt mixtures. But when PB was used beyond $15 \%$, the Marshall stability showed a decreasing trend for Margalla aggregates, increasing trend for Karak aggregates and decreasing trend for Burhan aggregates. This decline in stability is attributed to a decline in interlocking of aggregates due to lubricating effect. The corresponding flow for the Modified asphalt mixtures first showed a decreasing trend for Margalla aggregates at $15 \%$ PB modification but beyond $15 \%$, an increasing trend in flow as compared to conventional asphalt mixtures The decrease in flow or increase in Marshall Stability is attributed to improvement in interlocking and decline in flow or stability is attributed to a decline in interlocking offered by binder and PB coated aggregate particles in modified asphalt.
\end{abstract}

\section{Introduction}

Bitumen when used in conjunction with polymers would lead to many improvements in the asphalt mixture properties such as improvement in rut resistance, fatigue resistance, resistance to thermal cracking, resistance to stripping and decline in temperature susceptibility. The above significant features of polymer modified bitumen (PMB) make it possible to replace pure bitumen by PMB in many paving and maintenance applications. Performances of PMB by itself depend on various parameters such as polymer-bitumen characteristics, compatibility and mixing conditions [1]. The disposing of Plastic waste originated from the plastic bottles has become a major part of the

*Corresponding author: khyberpass08@gmail.org 
world's solid waste management problems. Several attempts were made to recycle these polymeric wastes for useful engineering purposes in asphalt pavement industry in order to get rid of their disposing problems. The polymeric wastes can be used as additive as well as partial replacement of bitumen in asphalt mixtures to improve performance of asphalt pavements [2]. Certain polymers are significantly used as a binder modifier in asphalt mixtures as a performance accelerator particularly for rut resistance and resistance to thermal cracking in asphalt pavements [3] Polypropylene was also subjected to thermal degradation during pyrolysis in wet basis where polypropylene was mixed with the asphalt in various proportions ranging from $1,3,5$ and $7 \%$ by weight of asphalt binder at temperature $160 \pm 5{ }^{\circ} \mathrm{C}$ for $5 \mathrm{~min}$. It was concluded that the tensile strength ratio for different mixtures containing polypropylene was greater by $85 \%$ than the conventional mixtures. The penetration index values recorded in the test indicate that polypropylene reduced the temperature susceptibility of the asphalt and therefore, there would not be any problem for mixture when exposed to moisture. The increase in Marshall Stability and decrease in flow value was also recorded [4].An improvement in Marshall Stability with specified flow was found for the pavement base and surface mix design when modified with plastic wastes bags as a particle having size of $1.2 \mathrm{~mm}-3 \mathrm{~mm}$ up to $2.5 \%$ by weight[5]. It has already been proved that the permanent deformation of asphalt mixture can be reduced by modifying asphalt with recycled Polyethylene Terephthalate (PET). PET is widely used in water and soft drink bottles and it's commonly recycled[6] The performance of conventional and plastic polymer (PP) modified asphalt mixture was compared and concluded that waste PP modified bituminous mixes are expected to be more durable and have an improved performance in field[7]. It has already been reported that plastic modified asphalt concrete has improved rutting resistance and resistance against low-temperature cracking as compared to the conventional asphalt mixtures. The field tests proved that plastic wastes used as an additive not only enhance the serviceable life of the roads but also solve the disposing of plastic bottles waste [8] It has also been concluded that the service life of pavement decreases with the increase in number and frequency of traffic but particularly heavy traffic such as trucks when having low number of axles greatly affect the design life. So, there are a number of options available to improve asphalt mixture performance such as to build thicker sections or to use additives as modifier in asphalt mixture [9]. Plastic is available in various forms such as packaging, protecting, agriculture, toys, domestic utensils which constitute waste when their useful life is over [10].Different forms of wastes like plastic bottles, Nylon, polythene bags, polyvinylchloride which need to be recycled for engineering purpose not only to get rid of these growing wastes but to recycle them for useful purpose in pavement industry. Asphalt pavement performance is affected by several factors such as the type and amount of binder, aggregate and additive in the asphalt mix. The field performance of asphalt mixtures can be enhanced due to utilization of various types of additives such as Polymers, latex, fibers and many chemical additives [11].The use of additives in asphalt mixture would be very economical and time saving as compared to having thicker sections in order to improve pavement performance and control its deterioration. Unfortunately, plastic is non-biodegradable material which would remain in the environment even when buried in the earth crust for a long period of time thereby causing environmental pollution. So, therefore, some innovative and sustainable approaches are required to be applied to reuse these growing quantities of wastes. The best solution for this problem is to recycle these wastes for adequate engineering products [12]. The performance of plastic bottles modified asphalt mixture was studied in terms of Marshall Stability and flow for both the soaked and unsoaked conditions. 
The two grades of bitumen $60 / 70$ and $80 / 100$ modified with six different percentages of plastic bottles ranging from $2 \%$ to $12 \%$ with an increment of $2 \%$ were used to prepare asphalt mixtures. The unsoaked samples gradually showed $15 \%$ increase in stability for $60 / 70$ grade bitumen and $10 \%$ increase in stability for $80 / 100$ grade bitumen respectively but, for the soaked conditions, the samples showed a gradual decrease in stability for both the 60/70 and 80/100 grades bitumen[13]Due to plenty use of plastic in our lives in various forms such as packaging bottles, Cups, tyres, plastic furniture and toys , medical devices which lead to a wide spread generation of plastic wastes which require a proper end-of-life management. These are non-biodegradable materials and cost much to be disposed. So, it is a good option to re-use it for useful engineering products [14]. PVC and waste polyethylene were used in conjunction with asphalt mixture as modifier in order to check the performance as well as the design criteria of modified asphalt mixtures. A remarkable improvement in performance in terms of Marshall Stability, Stiffness and voids characteristics was found for the modified asphalt mixture when modified with polyethylene up to $10 \%$ and up to $7.5 \% \mathrm{PVC}$ in asphalt mixture particularly in warmer region [15].

\section{Methodology}

The test procedure and preparation of samples were conducted as per the procedure described in ASTM D1559. The test procedure and preparation of samples were conducted as per the procedure described in ASTM D1559. Aggregates used in this study were obtained from three different locations (Margalla, Karak and Burhan) hills. The aggregates were provided as a mixture of different sizes of particles which were then sieved in the suit laboratory to the required sizes and then mixed according to the trial gradation. Bitumen was collected from local Attock Refinery of grade 60/70 is used as a binder to prepare asphalt mix then prepared modified Asphalt Mixtures using waste plastic bottles then testing the samples. The following flow chart shows the detailed approach for the study program.

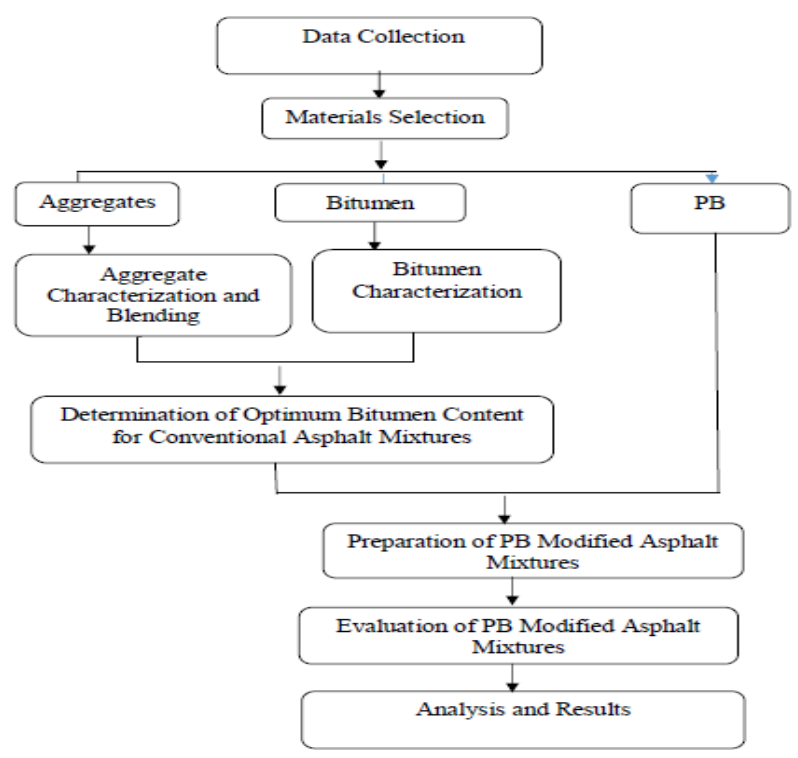

Fig. 1. Flow chart showing laboratory testing procedure 


\subsection{Material properties}

\subsubsection{Bitumen properties}

60/70 penetration grade bitumen was collected from local Attock Refinery and is used as a binder to prepare asphalt mix. The important properties of bitumen used are given below.

\subsubsection{Physical properties of bitumen}

Table 1. Properties of bitumen

\begin{tabular}{|l|c|}
\hline Property & Value \\
\hline Penetration at 250C $(\mathrm{mm})$ & 66.8 \\
\hline Softening Point $(0 \mathrm{C})$ & 48.62 \\
\hline Specific Gravity & 1.01 \\
\hline
\end{tabular}

\subsubsection{Physical properties of aggregate}

The aggregate samples were collected from three local quarries named Margalla, Karak and Burhan. The important properties of the aggregates used are given below

Table 2. Properties of aggregates

\begin{tabular}{|c|c|c|c|}
\hline Property & Margalla & Karak & Burhan \\
\hline Abrasion (\%) & 19.46 & 21.8 & 21 \\
\hline Flakiness Index (\%) & 2 & 4.5 & 3.7 \\
\hline Elongation Index (\%) & 11 & 12.7 & 14 \\
\hline Bulk Specific Gravity & 2.6 & 2.53 & 2.49 \\
\hline
\end{tabular}

\subsection{Preparation and testing of asphalt mixtures}

This study was based on the laboratory work conducted in the Highway and Transportation Engineering laboratory of SUIT Peshawar. The conventional and modified asphalt mixtures were prepared according to the Marshall procedure as per ASTM D 1559-89. The coarse and fine aggregate were mixed according to the adopted gradation described as per the procedure of ASTM. In order to prepare Conventional asphalt mixtures, the Marshall mould having a dia of 4 inch, thickness of 2.5 inch and volume of 1200 gram was filled with conventional and modified asphalt mixture and compacted with a compactive effort of 75 blows by the standard Marshall hammer on both sides of the Marshall briquettes. The hardened samples were extracted from the mould by sample extruder after twenty four hours the samples were kept in water at $600 \mathrm{C}$ for one hour before testing. Marshall Tester was then used for finding Stability and Flow of the samples. 4.2\% Optimum Binder Content $(\mathrm{OBC})$ was concluded for the conventional unmodified asphalt mixtures by using Marshall Test. Different percentages of the PBW ranging from 0, 15, 20,25 and 30\% of the weight of $\mathrm{OBC}$ was heated at $1600 \mathrm{C}$ along with bitumen before adding aggregate to get a modified binder. The modified binder was added to the pre-heated asphalt mixture and thoroughly mixing was done mechanically till the color and consistency of the mixture appeared to be uniform. The mixture was then poured in to a pre-heated Marshall mold and the samples were compacted by Marshall Compactor for heavy traffic and were kept over night for cooling to room temperature. 


\section{Results and data analysis}

A comparison among asphalt mixture performance when plastic bottles waste was used as additive in asphalt mixture prepared in aggregates obtained from Margalla, Karak and Burhan quarries is described below.

The result presented in table 3 reflects the stability and flow values for the conventional asphalt mixture prepared in specified three types of aggregates at an Optimum Binder Content $(\mathrm{OBC})$ of $4.2 \%$. The average stability of the unmodified asphalt mixtures prepared in Margalla aggregates is maximum, the Burhan is medium and the Karak is minimum. Where as the corresponding flow values has an increasing trend for the specified three types of asphalt mixtures. This decreasing trend in stability or increasing trend in flow for Margalla, Burhan and Karak samples is attributed to a decreasing trend in interlocking or cohesion offered by binder among the grains of the samples. The physical properties indicate that the flakiness index, elongation index, abrasion values are low for Margalla aggregates, medium for Karak aggregates and maximum for Burhan aggregates which is the main reason for the decreasing trend in stability and increasing trend in flow for Margalla , Burhan and Karak aggregates. It also shows that the Margalla aggregate are Superior to be used in asphalt mixture production.

Table 4 and Fig 3 give the Stability and Flow values for the $15 \%$ PB waste modified asphalt mixture for the three types of aggregates. It was concluded that $15 \%$ modification with PB is Optimum in terms of Marshall Stability and flow. The average Stability of the modified Margalla asphalt mixture when $15 \%$ PB were used is $13.8 \%$ higher as compared to conventional asphalt mixtures. Whereas the improvement in Karak sample at $15 \%$ PB modification is just $1 \%$ but there is fall in the stability values by $3.5 \%$ in Burhan sample as compared to conventional unmodified asphalt mixtures. The corresponding flow values at $15 \%$ PB modification shows a decreasing trend for Margalla and Karak but increasing trend for Burhan.

Table 5, 6, 7 and Fig 4, 5,6 shows that when PB were used beyond 15\%, the Marshall stability showed a decreasing trend. This decline in stability is attributed to a decline in interlocking of aggregates. The corresponding flow for the Modified asphalt mixtures first showed a decreasing trend for Margalla aggregates when 15\% PB was used but beyond $15 \%$, an increasing trend in flow as compared to conventional asphalt mixtures has been shown. The decrease in flow or increase in Marshall Stability is attributed to improvement in interlocking and decline in flow or stability is attributed to a decline in interlocking offered by binder and 'PB' coated aggregate particles.

Table 8 shows that Margalla samples give $13.8 \%$ higher strength at $15 \%$ PB modification as compared to conventional mix but the stability then declines at the remaining percentages of 20, 25 and 30. It also shows that there is little increase in stability of the Karak at 20 and $25 \%$ modification but it declines at 15 and $30 \%$ modification. The Burhan samples gradually show a decreasing trend at all percentages of modification. So, the effect of $15 \%$ PB modification of asphalt mix is very significant and recommended for construction.

Table 9 shows that Margallah samples give decrease in the average flow at $15 \% \mathrm{~PB}$ modification as compared to conventional mix but the flow then increase at the remaining percentages of 20,25 and 30 .

The he karak samples there was decrease at $20 \%$ as compared to conventional mix but the flow then increase at the remaining percentages 15, 25 and 30.The Burhan samples give decrease the average flow at $15 \%$ PB modification as compared to conventional mix but the flow then increase at the remaining percentages 20,25 and 30 . 
Table 3. Stability and Flow values for conventional unmodified asphalt mixtures at optimum bitumen content of $4.2 \%$, Stability $(\mathrm{Kg})$, Flow $(\mathrm{mm})$

\begin{tabular}{|c|c|c|c|}
\hline Sample & Margalla & Karak & Burhan \\
\hline 01 & 1651 & 1639 & 1672 \\
\hline 02 & 1583 & 1473 & 1562 \\
\hline 03 & 1693 & 1540 & 1628 \\
\hline 04 & 1678 & 1488 & 1599 \\
\hline Avg. & 1651.25 & 1535 & 1615.25 \\
\hline
\end{tabular}

\begin{tabular}{|c|c|c|c|}
\hline Sample & Margalla & Karak & Burhan \\
\hline 01 & 2.5 & 2.8 & 2.9 \\
\hline 02 & 2.9 & 3.1 & 3.1 \\
\hline 03 & 2.4 & 2.7 & 2.7 \\
\hline 04 & 2.6 & 2.9 & 2.6 \\
\hline Avg. & 2.6 & 2.87 & 2.82 \\
\hline
\end{tabular}
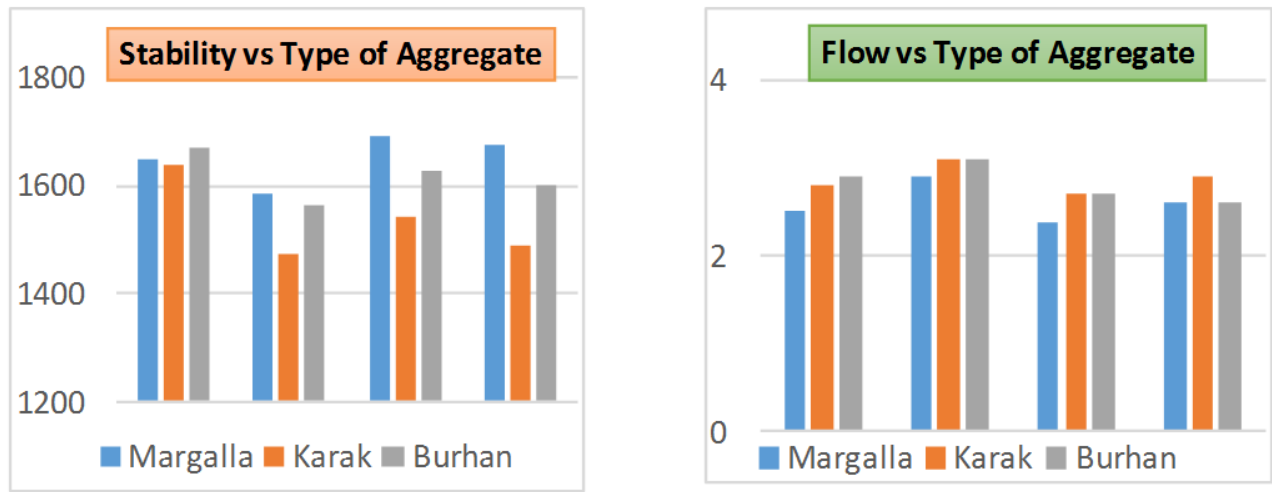

Fig. 2. Stability and Flow values for conventional unmodified asphalt mixtures, Stability (Kg), Flow (mm)

Table 4. Stability and Flow values for the $15 \%$ PB waste modified asphalt mixtures, Stability $(\mathrm{Kg})$, Flow $(\mathrm{mm})$

\begin{tabular}{|c|c|c|c|}
\hline Sample & Margalla & Karak & Burhan \\
\hline 01 & 1892 & 1510 & 1540 \\
\hline 02 & 1808 & 1553 & 1518 \\
\hline 03 & 1913 & 1562 & 1577 \\
\hline 04 & 1903 & 1571 & 1594 \\
\hline Avg. & 1879 & 1549 & 1557.25 \\
\hline
\end{tabular}

\begin{tabular}{|c|c|c|l|}
\hline Sample & Margalla & Karak & Burhan \\
\hline 01 & 2.2 & 2.7 & 2.6 \\
\hline 02 & 2.4 & 2.1 & 3.1 \\
\hline 03 & 2.0 & 2.5 & 2.5 \\
\hline 04 & 2.1 & 2.2 & 2.0 \\
\hline Avg. & 2.17 & 2.37 & 2.55 \\
\hline
\end{tabular}
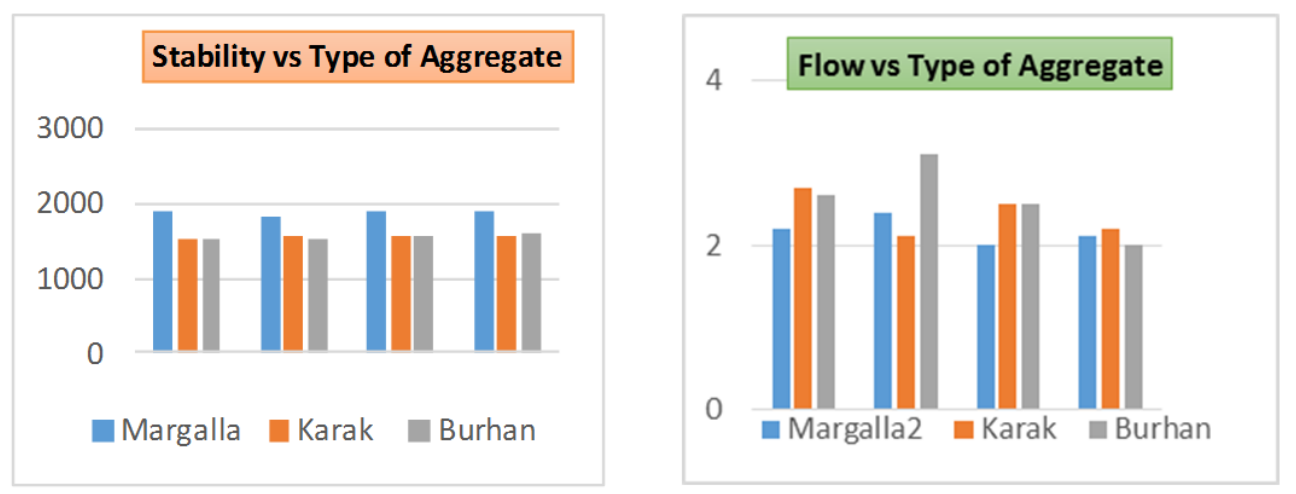

Fig. 3. Stability and Flow values for the $15 \%$ PB waste modified asphalt mixtures, Stability (Kg), Flow (mm) 
Table 5. Stability and Flow values for the $20 \%$ PB waste modified asphalt mixtures, Stability $(\mathrm{Kg})$, Flow $(\mathrm{mm})$

\begin{tabular}{|c|c|c|c|}
\hline Sample & Margalla & Karak & Burhan \\
\hline 01 & 1660 & 1503 & 1342 \\
\hline 02 & 1650 & 1546 & 1298 \\
\hline 03 & 1694 & 1523 & 1386 \\
\hline 04 & 1688 & 1582 & 1378 \\
\hline Avg. & 1673 & 1538.5 & 1351 \\
\hline
\end{tabular}

\begin{tabular}{|c|c|c|c|}
\hline Sample & Margalla & Karak & Burhan \\
\hline 01 & 2.4 & 2.4 & 3.1 \\
\hline 02 & 2.5 & 2.2 & 3.3 \\
\hline 03 & 2.7 & 2.1 & 3.0 \\
\hline 04 & 2.6 & 2.0 & 2.9 \\
\hline Avg. & 2.55 & 2.17 & 3.07 \\
\hline
\end{tabular}
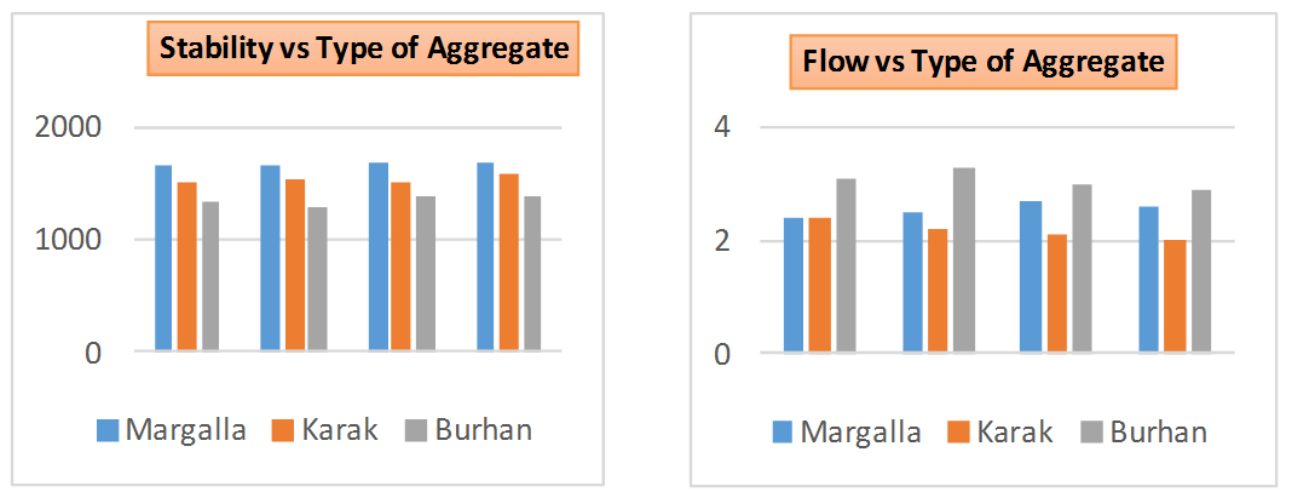

Fig. 4. Stability and Flow values for the $20 \%$ PB waste modified asphalt mixtures, Stability $(\mathrm{Kg})$, Flow $(\mathrm{mm})$

Table 6. Stability and Flow values for the $25 \%$ PB waste modified asphalt mixtures, Stability $(\mathrm{Kg})$, Flow (mm)

\begin{tabular}{|c|c|c|c|}
\hline Sample & Margalla & Karak & Burhan \\
\hline 01 & 1452 & 1607 & 1225 \\
\hline 02 & 1518 & 1510 & 1254 \\
\hline 03 & 1540 & 1556 & 1183 \\
\hline 04 & 1531 & 1613 & 1144 \\
\hline Avg. & 1510.25 & 1571.5 & 1201.5 \\
\hline
\end{tabular}

\begin{tabular}{|c|c|c|c|}
\hline Sample & Margalla & Karak & Burhan \\
\hline 01 & 2.9 & 2.3 & 3.4 \\
\hline 02 & 2.6 & 2.7 & 3.2 \\
\hline 03 & 2.5 & 2.4 & 3.7 \\
\hline 04 & 2.6 & 2.3 & 3.5 \\
\hline Avg. & 2.65 & 2.42 & 3.45 \\
\hline
\end{tabular}
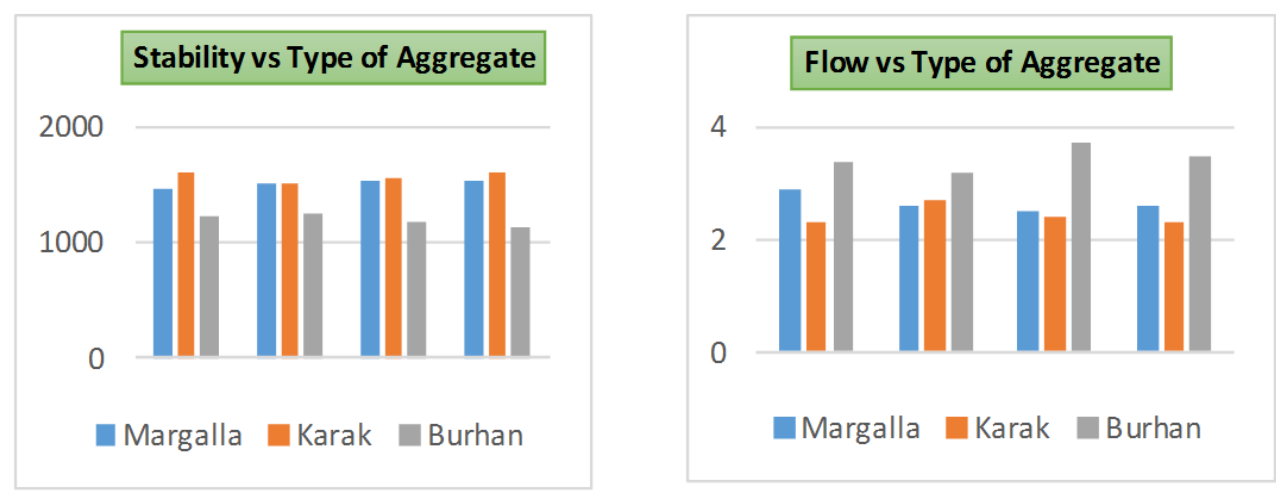

Fig. 5. Stability and Flow values for the $25 \%$ PB waste modified asphalt mixtures, Stability (Kg), Flow $(\mathrm{mm})$ 
Table 7. Stability and Flow values for the $30 \%$ PB waste modified asphalt mixtures, Stability

$(\mathrm{Kg})$, Flow $(\mathrm{mm})$

\begin{tabular}{|c|c|c|c|}
\hline Sample & Margalla & Karak & Burhan \\
\hline 01 & 1386 & 1496 & 1035 \\
\hline 02 & 1364 & 1373 & 1077 \\
\hline 03 & 1378 & 1387 & 1122 \\
\hline 04 & 1293 & 1403 & 1143 \\
\hline Avg. & 1355.25 & 1414.75 & 1094.25 \\
\hline
\end{tabular}

\begin{tabular}{|c|c|c|c|}
\hline Sample & Margalla & Karak & Burhan \\
\hline 01 & 3.0 & 3.1 & 3.4 \\
\hline 02 & 3.1 & 3.3 & 3.2 \\
\hline 03 & 2.9 & 3.0 & 3.0 \\
\hline 04 & 3.3 & 2.8 & 2.9 \\
\hline Avg. & 3.0 & 3.05 & 3.12 \\
\hline
\end{tabular}
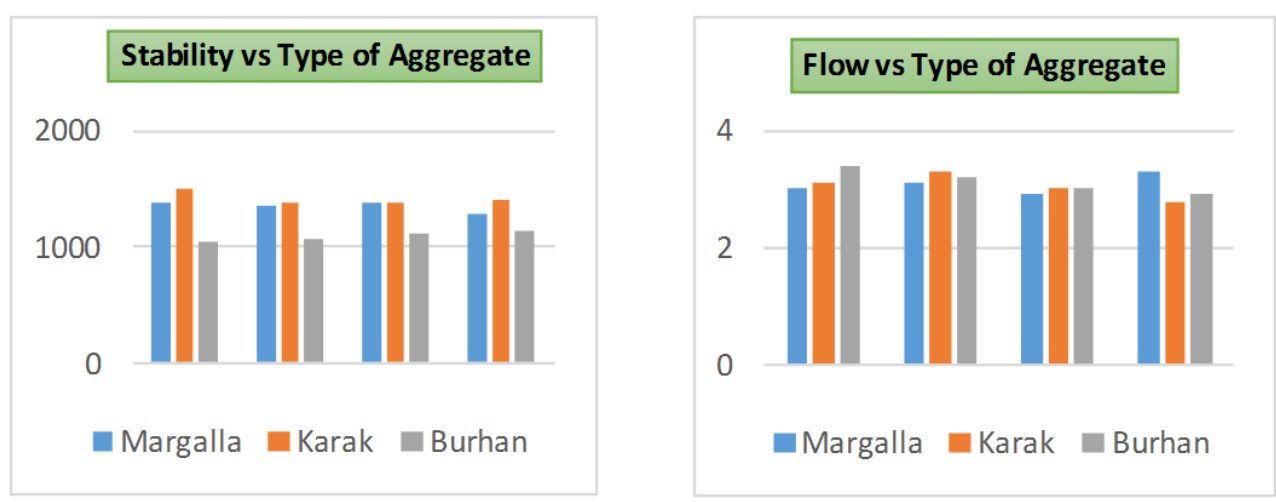

Fig. 6. Stability and Flow values for the $30 \%$ PB waste modified asphalt mixtures, Stability $(\mathrm{Kg})$, Flow (mm)

Table 8. Comparison of the Average Stability values for various percentages of PB waste modified asphalt mixtures, Stability (Kg), Flow (mm)

\begin{tabular}{|l|c|c|c|c|c|}
\hline \multicolumn{1}{|c|}{ Sample } & Conventional & $15 \% \mathrm{~PB}$ & $20 \%$ PB & $25 \%$ PB & $30 \%$ PB \\
\hline Margalla & 1651.25 & 1879 & 1673 & 1510 & 1355.25 \\
\hline Karak & 1535 & 1549 & 1538.5 & 1576.25 & 1414.75 \\
\hline Burhan & 1615.25 & 1557.2 & 1351 & 1201.5 & 1094.25 \\
\hline
\end{tabular}

Table 9. Comparison of the Average Flow values for various percentages of PB waste modified asphalt mixtures, Stability (Kg), Flow (mm)

\begin{tabular}{|l|c|c|c|c|c|}
\hline \multicolumn{1}{|c|}{ Sample } & Conventional & $15 \%$ PB & $20 \%$ PB & $25 \%$ PB & $30 \%$ PB \\
\hline Margalla & 2.6 & 2.17 & 2.5 & 2.65 & 3 \\
\hline Karak & 2.87 & 2.37 & 2.17 & 2.42 & 3.1 \\
\hline Burhan & 2.82 & 2.55 & 3.0 & 3.45 & 3.12 \\
\hline
\end{tabular}



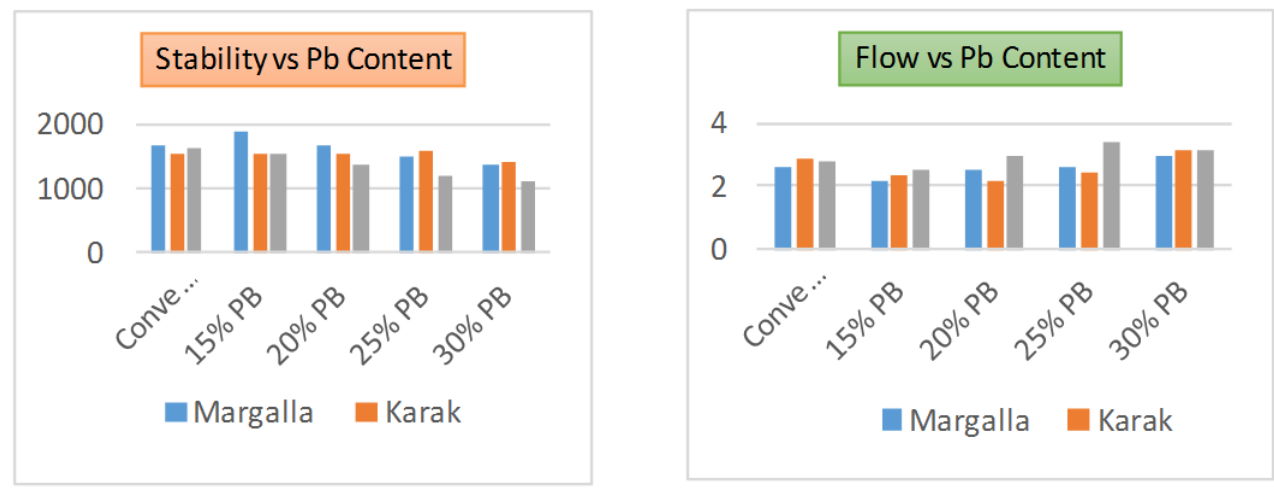

Fig. 7. Comparison of the Average Stability and Flow values for various percentages of PB waste modified asphalt mixtures, Stability $(\mathrm{Kg})$, Flow $(\mathrm{mm})$

\section{Conclusions}

The experimental work while comparing the performance of Conventional Asphalt Mixtures and PB Modified asphalt mixtures prepared in aggregates obtained from Margalla, Karak and Burhan quarries give the following outcomes:

- Plastic Bottles can be conveniently used as modifier for asphalt mixture production as a sustainable management of plastic wastes to avoid disposing problems.

- The Optimum Bitumen Content was found to be $4.2 \%$ and the Optimum Plastic Bottles waste was found to be $15 \%$ by weight of bitumen for the better

- performance in terms of Marshall stability with specified flow of asphalt mixturesThe average Stability of the modified Margalla Asphalt Mixtures when 15\% PB waste was used is $13.8 \%$ higher as compared to conventional asphalt mixtures. But when PB waste was used beyond $15 \%$, the Marshall stability showed a continuous decreasing trend.

- The Margalla and Karak aggregates give higher stability at $15 \%$ PB waste modification as compared to the asphalt mixture prepared in Burhan aggregates.

- There is a gradual increase in stability of asphalt mixture prepared in Karak aggregates at $15 \%, 20 \%$ and $25 \%$ PB modification but, a sudden fall has been observed in stability of asphalt mixture at $30 \% \mathrm{~PB}$ modification.

- A continuous fall in stability of asphalt mixture prepared in Burhan aggregates at $15 \%$, $20 \%, 25 \%$ and $30 \%$ PB modification has been observed.

- Margalla aggregate are recommended to be used at 15\% PB modification for good performance of asphalt mixtures.

The authors of this study acknowledge the center of graduate studies(CGS) UTHM Malaysia that contributed to the success of this research work to support the technical and financial.

\section{References}

[1] Y. Becker, M. Mendez and Rodriguez, Polymer modified asphalt, Vision Tecnologica, 9(1), (2001)

[2] S. Bose and S. Raju, Utilization of plastic waste in bituminous concrete mixes, Roads and Pavements, 3, (2004) 
[3] M. Awwad and Shabeeb, The use of polyethylene in hot asphalt mixtures, American Journal of Applied Sciences, 4(6), 390-396 (2007)

[4] A. Al-Hadidy and Tan, The effect of plastomers polymer type and concentration on asphalt and moisture damage of sma mixtures, Al-Rafidain Engineering Journal, 19(5), (2011)

[5] Q. Adnan and I. Mansoor, utilization of plastic waste bags in itummous mix for improved performance of roads, Better Road, (2008)

[6] T.F. Chen, Evaluation of rutting performance on hot mix asphalt modified with plastic bottles, B.Sc Thesis, University of Technology of Malaysia, Johor Bahru, (2009).

[7] S. Rashid, T.A. Khan, Sangita, D.K. Sharma, Performance evaluation of waste plastic/polymer modified bituminous concrete mixes, Journal of Scientific and Industrial Research, 68(11), 975-979 (2009)

[8] V.S. Punith and A. Veeraraghavan, Laboratory fatigue studies on bituminous concrete mixed utilizing waster shredded plastic modifier, Proc. of 21st ARRB Transport Research (ARRB), 38(5), (2010)

[9] T.B. Moghaddam, M.R. Karim and Mahrez, A review on fatigue and rutting performance of asphalt mixes, Scientific Research and Essays, 6(4), 670-682 (2011)

[10] A.F. Abdalqader, Landfills Needs Assessment In Gaza Strip And Sites Selection Using Gis, M.Sc Thesis, Islamic University of Gaza, Palestine (2011)

[11] Taih, The effect of additives in hot asphalt mixtures, Journal of Engineering and Development, 15(3), (2011)

[12] V. Swami, A. Jirge, K. Patil, S. Patil and K. Salokhe, Use of waste plastic in construction of bituminous road, International Journal of Engineering Science and Technology, 4(5), 2352-2355, (2012)

[13] K.S. Prasad, K.R. Manjunath and K.V.R Prasad, Study on marshall stability properties of BC mix used in road construction by adding plastic waste bottles, IOSR Journal of Mechanical and Civil Engineering, 2(2), 12-23 (2012)

[14]Plastic Common Wastes \& Materials US EPA [Online]. Available (2013), www.epa.gov/osw/conserve/material/plastic.htm

[15]R. Md. Nobinur, Performance evaluation of waste polyethylene and PVC on hot asphalt mixtures, American Journal of Civil Engineering and Architecture, 97-102, (2013) 